\title{
Quantitative Literacy: Does it Work? Evaluation of Student Outcomes at Colby-Sawyer College
}

\author{
Benjamin Steele \\ Colby-Sawyer College, bsteele@colby-sawyer.edu \\ Semra Kilic-Bahi \\ Colby-Sawyer College, skilic-bahi@colby-sawyer.edu
}

Follow this and additional works at: https://digitalcommons.usf.edu/numeracy

Part of the Mathematics Commons, and the Science and Mathematics Education Commons

\section{Recommended Citation}

Steele, Benjamin, and Semra Kilic-Bahi. "Quantitative Literacy: Does it Work? Evaluation of Student Outcomes at Colby-Sawyer College." Numeracy 3, Iss. 2 (2010): Article 3. DOI: http://dx.doi.org/10.5038/ 1936-4660.3.2.3 


\title{
Quantitative Literacy: Does it Work? Evaluation of Student Outcomes at Colby- Sawyer College
}

\begin{abstract}
Colby-Sawyer College has adopted a mission for quantitative literacy (QL) to give students the "necessary skills to understand and use quantitative information in their personal and professional lives." We have implemented an across-the-curriculum approach to develop these skills. As part of this QL program, we administer two assessment tests, one in basic mathematical skills and one that applies those skills, plus an attitude survey to both freshmen and seniors. Three years of data show that seniors score about 10 percentage points higher than freshmen on these tests. However, seniors still scored below 55 percent on both tests, and many cannot answer what we feel are questions that an informed citizen should be able to answer. As evaluation of progress in quantitative skills becomes more common, we suspect that similar results will be found at other colleges. We propose that this deficit in skills results from a lack of practice of the skills students learned before college or a reliance on calculators for simple calculation. If we want to improve the QL preparation of college students, we suggest that there needs to be more widespread evaluation of QL skills at the college level, an increase in QL teaching and learning in the college curriculum, and collaboration with educators at the pre-college level.
\end{abstract}

\section{Keywords}

Quantitative literacy, assessment, evaluation student outcomes, test, survey.

\section{Creative Commons License}

\section{(c) (i) (8)}

This work is licensed under a Creative Commons Attribution-Noncommercial 4.0 License

\section{Cover Page Footnote}

Ben Steele, a biologist, is Professor and Chair of the Department of Natural Sciences at Colby-Sawyer. His teaching includes courses in ecology, animal behavior, evolution, conservation biology, and environmental science. His research interest is bird conservation, and his current project involves the chick-raising behavior of the Common Eider in Finland.

Semra Kilic-Bahi, a mathematician, is an associate professor in the Department of Natural Sciences at Colby-Sawyer and teaches QL in mathematics courses. She was Secretary-Treasurer of the QL-SIGMAA of the Mathematics Association of America (2007-2009) and is the lead PI in the College's NSF project to infuse QL across the curriculum. 


\section{Introduction}

The need for students to be literate in quantitative concepts has been stressed by many voices (e.g., Schneider 2004; Ball 2003; Madison 2009). Our ability to understand issues facing us as citizens is increasingly dependent on understanding the data and relationships behind the issues. For example, in 2009-2010, debates over the financial crisis, the climate summit meeting in Copenhagen, and health care reform all involve quantitative understanding. Furthermore, many potential careers involve use and manipulation of quantitative data. This is not only true in fields that traditionally involve numbers, (e.g., science and engineering) but also in other fields. For example, English scholars might graph frequency of word use.

On the other hand, many indications suggest that college students are not well equipped to understand and use numbers (Ball 2003). This ability gap has given rise to the field known as quantitative literacy (QL), which focuses on teaching students to use simple mathematical concepts to solve real problems. It makes intuitive sense that, for people not involved in technical fields such as physics, QL skills are more important than higher-level math courses such as calculus. As a result, many institutions have adopted a QL curriculum, with QL rather than math courses, or have QL skills embedded in courses with other content (e.g., Macalester College [Bressoud 2009]; also see Steen 2007). At Colby-Sawyer College, entry-level math courses have been converted to QL courses and a series of faculty-development workshops has been used to encourage faculty in all disciplines to include QL activities in their classes. The design and implementation of these workshops, funded by a grant from the National Science Foundation, are described in Steele and Kılıç-Bahi (2008).

The effectiveness of QL as opposed to traditional math at meeting our goals for students, however, has rarely been tested, although the national push for assessment and accountability has led to greater assessment efforts. Taylor (2009) sees assessment as part of the evolution of QL: plan, do, check, and act. The check step has just started in many QL programs and here we present an example of the progress at Colby-Sawyer College. We have developed a QL assessment tool that has been administered to first-year students and seniors for three years, and the results enable us to take a preliminary look at how well we are doing. 


\section{Evaluation and Assessment}

Evaluation of students or programs is based on assessments of student achievement or attitudes. Evaluation has several purposes including placement of students in correct math courses, evaluation of students' achievements at the end of their college career, and evaluation of the effectiveness of a QL program, the latter by assessing students when they enter college and again when they graduate (Bressoud 2009). This third type of evaluation is useful not only for assessing whether students are meeting stated goals or outcomes, but also for showing how their college education has contributed to meeting these goals and identifying how the curriculum can be improved. It is also the most intensive, involving tests given at least twice during a student's career in college.

There are several types of assessments. First, QL, or at least proficiency at skills, is fairly simple to assess with a test including a set of questions with definite correct answers. Second, surveys can be used to assess students' attitudes, confidence, interest, and enjoyment of math. An example is the "Mathematics Attitude Survey" developed at Dartmouth College (Wallace et al. 2009). Finally, student writing in portfolios can be assessed with a rubric such as the Association of American Colleges and Universities' (AAC\&U) Quantitative Literacy VALUE (Valid Assessment of Learning in Undergraduate Education) Rubric for assessing $\mathrm{QL}^{1}$, and Carleton College's rubric for assessing quantitative reasoning in their students' sophomore writing portfolios ${ }^{2}$. Grawe et al. (2010) argue that assessment of student writing evaluates students' ability to use QL concepts without being asked and therefore measures the acquisition of QL as a "habit of mind" (e.g., Hughes-Hallett 2001).

\section{Student Outcomes}

Our mission statement for QL at Colby-Sawyer states that students should have the "necessary skills to understand and use quantitative information in their personal and professional lives". ${ }^{3}$ We define QL as being able to use simple mathematical skills to solve real world problems. The skills we consider important at Colby-Sawyer contribute to five major learning outcomes (Table 1).

\footnotetext{
${ }^{1}$ http://www.aacu.org/value/metarubrics.cfm accessed May 31, 2010

${ }^{2} \mathrm{http}: / /$ serc.carleton.edu/departments/assessment/instruments/quant_reasoning.html accessed May 31, 2010

${ }^{3}$ http://www.colby-sawyer.edu/academics/experience/proficiencies.html accessed May 31, 2010
} 
Table 1

Learning Objectives and Associated Skills or Attributes. Number of Items on the Basic Skills and QL Skills Tests and Attitude Survey for Each Objective and Skill or Attribute.

\begin{tabular}{|c|c|c|c|}
\hline \multirow[t]{2}{*}{ Learning Objective } & \multirow[b]{2}{*}{ Skill } & \multicolumn{2}{|c|}{$\begin{array}{l}\text { Number of } \\
\text { questions* }\end{array}$} \\
\hline & & $\begin{array}{l}\text { Basic } \\
\text { Skills }\end{array}$ & $\begin{array}{c}\text { QL } \\
\text { Skills }\end{array}$ \\
\hline \multicolumn{2}{|c|}{$\begin{array}{l}\text { Apply basic arithmetical, algebraic and geometric tools in everyday } \\
\text { settings and distinguish between the appropriate and inappropriate } \\
\text { uses of numerical information. }\end{array}$} & 21 & 16 \\
\hline & $\begin{array}{l}\text { Perform basic arithmetic: fractions, } \\
\text { decimals, percentages, unit } \\
\text { conversion, scientific notation. }\end{array}$ & 14 & 12 \\
\hline & $\begin{array}{l}\text { Be familiar with the use and misuse } \\
\text { of numbers in the real world. }\end{array}$ & 1 & 0 \\
\hline & Be proficient at estimation. & 0 & 1 \\
\hline & $\begin{array}{l}\text { Perform basic algebraic and } \\
\text { symbolic manipulations, i.e. solving } \\
\text { equations. }\end{array}$ & 5 & 6 \\
\hline & $\begin{array}{l}\text { Use geometric concepts to solve } \\
\text { problems, i.e. length, height, } \\
\text { perimeter, area, volume. }\end{array}$ & 3 & 2 \\
\hline \multicolumn{2}{|c|}{$\begin{array}{l}\text { Use inductive and deductive reasoning and understand fallacies in } \\
\text { logic. }\end{array}$} & 2 & 4 \\
\hline & $\begin{array}{l}\text { Analyze a logical argument and its } \\
\text { premises }\end{array}$ & 2 & 4 \\
\hline & Detect fallacies in logic & 2 & 4 \\
\hline \multicolumn{2}{|c|}{ Understand, and use descriptive statistics and graphical displays. } & 2 & 4 \\
\hline \multicolumn{2}{|c|}{$\begin{array}{l}\text { Use reasoning to develop and test hypotheses and to draw inferences } \\
\text { and make well reasoned decisions from collected data. }\end{array}$} & 0 & 2 \\
\hline \multicolumn{2}{|c|}{$\begin{array}{l}\text { Improve students' attitude toward and confidence in using } \\
\text { quantitative tools }\end{array}$} & \multicolumn{2}{|c|}{ Attitude survey } \\
\hline \multicolumn{4}{|c|}{ Attribute } \\
\hline & Self-confidence & \multicolumn{2}{|c|}{4} \\
\hline & Anxiety & \multicolumn{2}{|c|}{4} \\
\hline & Value & \multicolumn{2}{|c|}{4} \\
\hline & Enjoyment & \multicolumn{2}{|c|}{4} \\
\hline & Motivation & \multicolumn{2}{|c|}{4} \\
\hline
\end{tabular}

* Some questions address multiple skills.

To define these outcomes further, we expect that most students should be able to perform the following example tasks:

- Students should be able to understand percent and percent change so that they can understand statements like "Sales were $21 \%$ higher than last year," and not feel comforted if their retirement account was reduced by 
30 percent by the 2008 financial crisis, but subsequently increased 30 percent.

- Students should be able to understand basic concepts of sampling and error and how error can be presented, for example, what it means to have an error of 3 percent in a public opinion poll.

- Students should be able to understand multiple ways of presenting data in graphs and tables. They should be able to draw conclusions from data presented in newspaper, TV, or Internet articles, and even be able to point out flaws or omissions in the presentation.

- Students should have "number sense," understand orders of magnitude, and be able to estimate approximate answers. They should know about how much difference there is between a National Science Foundation budget of $\$ 6900$ million and a defense budget of $\$ 515.4$ billion. They should be able to divide and multiply by powers of ten.

- Students should understand what a simple algebraic equation means and how it can be manipulated to solve for different variables. They should be able to convert units so that they know what the speed limit is when they travel in a country that uses the metric system.

- Students should be able to recognize fallacies in deductive and inductive reasoning and be able to use both to arrive at valid conclusions.

These are very simple and basic tasks that many educated people can agree on. In fact, these tasks rely on skills that are covered in high school math classes or earlier. For college graduates, a longer list of skills might be expected. More importantly, we expect students to develop a habit of mind that triggers them to use these skills when needed, without prompting.

\section{Methods}

To evaluate whether students at Colby-Sawyer have attained the skills in Table 1, we have designed three assessment tools. The first tool is a basic skills test of 25 multiple-choice questions covering the skills included in the first four outcomes in Table 1. These questions range from simple mathematical manipulations, such as dividing fractions, to ones that use those manipulations in context. Samples are included in Table 2.

The second tool is a QL skills test, also 25 multiple-choice questions, that assesses whether students can apply basic skills to solve problems (examples in 
Table 3). These questions were adapted from tests used at Hamilton, Trinity, Bowdoin, and Johnson State Colleges, from a text (Bennett and Briggs 2005) and from questions created by one of us [S K-B]. Questions were then mapped onto the learning objectives and associated skills (Table 1) and further modified to cover the skills in approximate relationship to what we considered to be their importance. Students were allowed to use calculators for the QL skills test, but not the basic skills test.

Table 2

Sample Questions from the Basic Skills Test. Percent Correct Answers, Seniors, 2009*

\begin{tabular}{|c|c|}
\hline Question & Percent \\
\hline $\begin{array}{l}\text { If the average of five numbers is } 22 \text {, and four of these } \\
\text { numbers are: } 23,48,10 \text {, and } 14 \text {, find the value of the } \\
\text { missing fifth number. }\end{array}$ & 74 \\
\hline $\begin{array}{l}\text { Evaluate the following expression: } \\
45+12 \times 5-36 \div 3\end{array}$ & 55 \\
\hline $\begin{array}{l}\text { What is the value of seven-fourths divided by eleven- } \\
\text { eights? }\end{array}$ & 32 \\
\hline \multicolumn{2}{|c|}{$\begin{array}{l}\text { * These examples were chosen to show questions on which students scored low } \\
\text { medium, and high. A complete list of questions is available from the authors. }\end{array}$} \\
\hline \multicolumn{2}{|c|}{$\begin{array}{l}\text { Table } 3 \\
\text { Sample Questions from the QL Skills Test. Percent Correct } \\
\text { Answers, Seniors, 2009* }\end{array}$} \\
\hline Question & Percent \\
\hline $\begin{array}{l}\text { Consider the statement, "All politicians are liars." Which of } \\
\text { the following people would be proof that the statement is } \\
\text { false? }\end{array}$ & 75 \\
\hline $\begin{array}{l}\text { - A politician who doesn't lie. } \\
\text { - A liar who is not a politician. } \\
\text { - A bank employee who never steals and never lies. } \\
\text { - A politician who never talks. } \\
\text { - None of the above. }\end{array}$ & \\
\hline
\end{tabular}

The national debt is the amount of money owed by the U.S. government. As of August 30, 2007, the U.S. national debt amounted to almost $\$ 9$ trillion. The population this year is estimated to be approximately 300 million. Suppose every person in America is asked to contribute an equal amount to pay off the national debt. Estimate the debt per person in 2007. NOTE: In the U.S., 1 trillion is equal to 1,000 billion.

Suppose water flows from a shower at a rate of 0.32 cubic feet per minute. Do you use more water by taking a 12-minute shower or by filling a bathtub with 0.4 cubic yards of water, and by how much? NOTE: 1 yard $=3$ feet

* These examples were chosen to show questions on which students scored low, medium, and high. A complete list of questions is available from the authors. 
The third tool is an attitude survey that measures five attributes of quantitative learning: self-confidence, anxiety, value, enjoyment, and motivation. This survey consists of 20 questions adapted from Dartmouth College's Mathematics Attitude Survey (Wallace et al. 2009) and from Tapia and Marsh (2004). Half of the questions were given before the two skills tests and the other half at the end of the testing session. Each half had two questions for each of the five attributes (Table 1). For this analysis, both halves were combined.

In Fall 2007, these assessment instruments were given to freshmen during regularly scheduled classes in most first-year Pathway Seminars, a suite of courses that are taken by all freshmen. In Fall 2008 and 2009, they were given to all first-year students in groups of 25 during orientation. The same tests were also given to most seniors in Spring 2008 and 2009 as part of their capstone class, a required class within each major. Thus, none of these seniors had taken the tests as freshmen so direct comparisons of individuals are not possible. We did not test all seniors as this method of delivery relies on each instructor committing class time for the assessment (about one hour). All tests were proctored by members of the QL committee, and students were instructed to do their best, but also told that there would be no consequences from low scores. A fourth element of our evaluation is to asses a sample of students' required electronic portfolios for quantitative reasoning, but those data have not been collected.

We evaluated the validity of the quantitative tests by correlating student scores with their GPA and SAT scores (Wallace et al. 2009). To see if all questions measured an individual's quantitative ability, we calculated correlations between responses to each individual item and the student's total score. Cronbach's alpha was used to measure internal consistency and reliability. This statistic indicates the ability of a set of questions to measure the same quality in the students who take the test (Wallace et al. 2009).

Test results were analyzed with ANOVA (SPSS Version 16.0.2, 2008), since the results conformed to the assumptions of parametric tests. Independent variables included class (freshman or senior), skills (basic or QL), and year (in which the test was given). Since the effects of year were non-significant, hypothesis tests were performed with just class and skill as factors.

In order to estimate the amount of quantitative content in the curriculum, we administered a survey to all faculty members in 2007 and again in 2009. This survey included the question, "How often did your students use the following 
quantitative skills in your courses last year?" and listed nine skills, each paired with a Likert scale with the five options ranging from "never" to "often".

\section{Results}

\section{Evaluating the Tests}

Correlations between the cumulative college GPA and two skills tests were all positive and ranged from 0.14 to 0.24 (Table 4). Positive values can be interpreted to mean that these two scores measure similar attributes, but the low values are expected since GPA results from all college courses. Correlations between Math SAT scores and test scores were also all positive and generally higher, ranging from 0.09 to 0.66 . Verbal SAT scores had weaker correlations with the assessment tests, as expected, although correlations with the QL tests, involving "word problems" had higher correlations (-0.07 to 0.50$)$ than with the basic skills (0.05 to 0.39$)$. These results suggest that the tests have construct validity (Wallace et al. 2009) in that they measure attributes that are also measured by GPA and SAT.

Table 4

Correlation Coefficients Between Cumulative College GPA, Scores on Verbal (V) and Mathematics (M) SAT and the Basic and QL Skills Tests*

\begin{tabular}{|c|c|c|c|c|c|c|}
\hline & \multicolumn{6}{|c|}{ Correlations } \\
\hline & \multicolumn{2}{|c|}{ GPA and } & \multicolumn{2}{|c|}{ SAT-V and } & \multicolumn{2}{|c|}{ SAT-M and } \\
\hline & Basic & QL & Basic & QL & Basic & QL \\
\hline \multicolumn{7}{|l|}{$1^{\text {st }}$-year students } \\
\hline Fall 2007 & 0.24 & 0.14 & 0.15 & 0.21 & 0.49 & 0.22 \\
\hline Fall 2008 & 0.15 & 0.24 & 0.13 & 0.16 & 0.36 & 0.26 \\
\hline Fall 2009 & \multicolumn{2}{|c|}{$\begin{array}{l}\text { GPA not } \\
\text { available }\end{array}$} & 0.39 & 0.50 & 0.66 & 0.55 \\
\hline \multicolumn{7}{|l|}{ Seniors } \\
\hline Spring 2008 and $2009 * *$ & 0.16 & 0.21 & 0.05 & -0.07 & 0.24 & 0.09 \\
\hline
\end{tabular}

The correlations between students' responses to an individual item with their total scores indicated that most of the questions functioned together to measure one quality. Three items on the basic skills test and four on the QL skills test had 
low or negative correlation coefficients indicating that students who did well on the test tended to get these items wrong. This suggests that these questions may not effectively evaluate a student's ability or that they test an ability that is different from most other questions. We plan to evaluate these questions further, but changing questions makes comparisons across years problematic. The majority of the questions had positive correlation coefficients, implying internal consistency.

Table 5

Cronbach's Alpha for Two Tests and Two Groups of Students

\begin{tabular}{lcc}
\hline & Basic Skills Test & QL Skills Test \\
\cline { 2 - 3 } First-Year Students $(N=803)$ & $\alpha=0.70$ & $\alpha=0.65$ \\
Seniors $(N=141)$ & $\alpha=0.75$ & $\alpha=0.78$ \\
\hline
\end{tabular}

Cronbach's alpha values (Table 5) were mostly above the target of 0.70 (Wallace et al. 2009). Thus questions in each test functioned together to measure quantitative ability.

\section{Test Results}

A summary of results from 2007, 2008, and 2009 showed higher scores for seniors than first year students (ANOVA, $\mathrm{F}_{1,1842}=88.75, p<0.0005$, Fig. 1, Table 6), indicating an improvement of quantitative ability in the course of their college career. Scores on the basic skills test were higher than those on the QL skills test (ANOVA, $\mathrm{F}_{1,1842}=23.07, p<0.0005$ ). The average on the basic skills test for all seniors was seven percentage points higher than that for freshmen (46 compared to 53). On the QL skills test, seniors were 12 percentage points higher than freshmen (38 for freshmen and 50 for seniors). This greater improvement on the QL test compared to the skills test was supported by the ANOVA analysis in that the interaction term between test (basic or QL) and class (freshman or senior) was marginally significant (ANOVA for skills $\times$ class, $\mathrm{F}_{1,1842}=3.76, p=0.053$ ). Thus, the difference between freshmen and seniors was greater on the QL test, suggesting that students improved more in applying skills than in the skills themselves. These results could indicate that students who were seniors in 2008-2009 have better quantitative skills than ones who were freshmen in the same years. However, since admission standards have not changed at ColbySawyer, this interpretation is unlikely, and the results suggest an improvement in quantitative ability. 


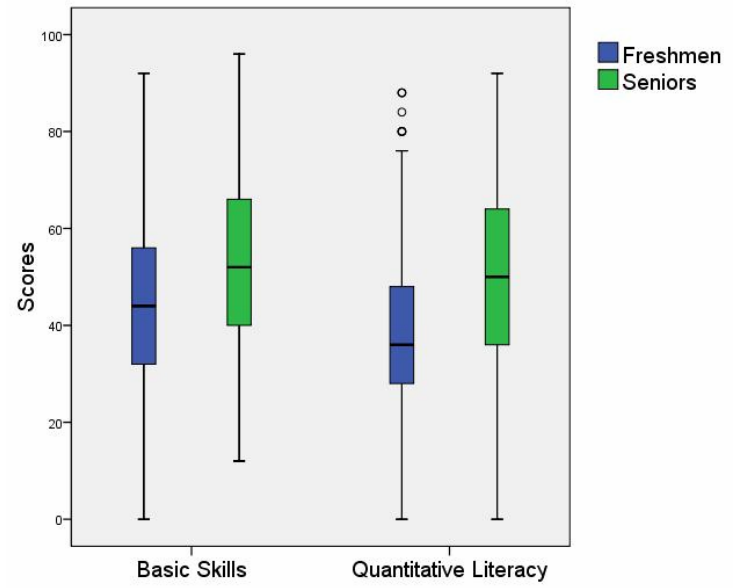

Figure 1. Box plots showing results of the two skills tests, freshmen and seniors, 2007-2009.

Table 6

Results of Basic and QL Skills Tests for Freshmen and Seniors

\begin{tabular}{lccccc}
\hline Cohort & N & Ave & Min & Max & Std Dev \\
\hline Freshmen & \multicolumn{5}{c}{ Basic Skills } \\
Fall 2007 & 96 & 45.5 & 8 & 92 & 15.9 \\
Fall 2008 & 312 & 46.4 & 0 & 88 & 17 \\
Fall 2009 & 398 & 44.5 & 8 & 84 & 15.9 \\
Seniors & & & & & \\
Spring 2008 & 24 & 53.0 & 32 & 76 & 13 \\
Spring 2009 & 117 & 52.5 & 0 & 96 & 18.5 \\
\hline & & $Q$ QL Skills & & & \\
Freshmen & & & & & \\
Fall 2007 & 95 & 34.9 & 0 & 88 & 16.1 \\
Fall 2008 & 298 & 39.5 & 0 & 88 & 15.2 \\
Fall 2009 & 389 & 37.9 & 4 & 88 & 14.1 \\
Seniors & & & & & \\
Spring 2008 & 24 & 48.5 & 0 & 84 & 23 \\
Spring 2009 & 114 & 49.8 & 0 & 92 & 18.4 \\
\hline
\end{tabular}

The attitude survey showed very little difference between freshmen and seniors (Fig. 2). Seniors scored slightly higher on questions about the value of 
quantitative skills suggesting that their encounters with these skills during college increased their understanding of how mathematics is important. Self-confidence showed a very slight difference between freshmen and sophomores. The other attributes, anxiety, enjoyment and motivation, showed no difference or lower values in seniors.

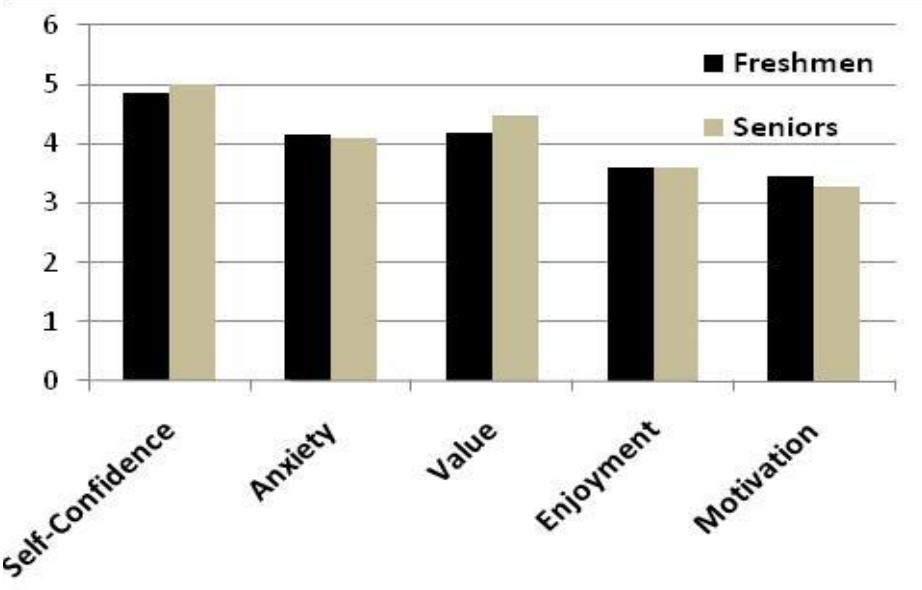

Figure 2. Scores of 808 freshmen and 153 seniors on attitude survey questions grouped by attribute. Data are combined from 2007, 2008 and 2009 for freshmen, and 2008 and 2009 for seniors. Higher values mean higher self-confidence, value, enjoyment, and motivation, and less anxiety.

Because there was no control group, we cannot be sure that the higher scores for seniors resulted from the curriculum and co-curriculum at Colby-Sawyer. Age, maturity, and off-campus experiences could also have contributed. However, students do encounter quantitative skills in the curriculum. All students take at least one math course (most are QL courses) and about $20 \%$ of the faculty who took the survey reported that their students often used quantitative skills in their classes (Table 7). These experiences certainly contributed to the higher scores in seniors. These higher scores can be only partially attributed to our NSF-funded QL Across the Curriculum program, which began in 2007 (Steele and Kılıç-Bahi 2008). The faculty survey indicated that the amount of quantitative material in the curriculum has increased between 2007 and 2009 (Table 7). For the question asking how often their students used (the following) quantitative skills in their courses last year, faculty responses of "never" decreased by nine percentage points or more for two skills, and answers of "often" increased by eight to 12 
percentage points on three skills. However, the seniors in our sample were exposed to this increase in QL content for only one or two years.

Table 7

\begin{tabular}{|c|c|c|}
\hline & 2007 & 2009 \\
\hline $\begin{array}{l}\text { Items with the highest percentage of faculty } \\
\text { responding "Never" }\end{array}$ & \multicolumn{2}{|c|}{$\begin{array}{l}\text { Percent of faculty } \\
\text { responding "Never" }\end{array}$} \\
\hline $\begin{array}{l}\text { Used basic arithmetical, algebraic, and/or } \\
\text { geometric tools to address problems in course } \\
\text { subject matter. }\end{array}$ & 28 & 15 \\
\hline $\begin{array}{l}\text { Distinguished between appropriate and } \\
\text { inappropriate uses of numeric information. }\end{array}$ & 24 & 15 \\
\hline $\begin{array}{l}\text { Items with the highest percentage of faculty } \\
\text { responding "Often }\end{array}$ & \multicolumn{2}{|c|}{$\begin{array}{l}\text { Percent of faculty } \\
\text { responding "Often' }\end{array}$} \\
\hline Detected fallacies in logic. & 18 & 30 \\
\hline Understood and used descriptive statistics. & 22 & 30 \\
\hline Understood and used graphical displays. & 26 & 34 \\
\hline $\begin{array}{l}\text { Used reasoning to develop and test hypotheses, } \\
\text { draw inferences, and make well-reasoned } \\
\text { decisions. }\end{array}$ & 26 & 40 \\
\hline
\end{tabular}

The difference in scores between freshmen and seniors notwithstanding, the graduating students leave on average being able to solve less than 55 percent of the problems. These problems are designed to be the kind that educated citizens could solve (Tables 2 and 3 ).

These results should not be taken as an absolute measure of students' abilities. On a test that carries no consequence for students, results do not always reveal real student abilities (Sundre and Kitsantas 2004). Students may not try very hard or may even not take the test seriously. The minimum scores of 0 suggest that this may have happened for some of our students. However, in the last iteration of the test (2009), test proctors made a more concerted effort to get students' best efforts and the results showed no improvement (Table 3).

A similar low level of QL ability may exist for seniors at many other colleges. Colby-Sawyer students are not specifically selected for high academic aptitude; SAT scores average around 1000 with SAT scores on the quantitative test averaging 500. We suspect that expanded assessment of quantitative ability and literacy at other colleges with higher and lower SAT averages will yield similar results. 


\section{Why Are Scores Low?}

If students are not meeting our expectations, the question is why? These are skills they are not expected to learn in college; most are covered in high school or junior high math classes. It makes sense that college students should improve their ability to apply the skills they know (i.e., the greater improvement on the QL skills test compared to the basic skills test), but it still is surprising that they seem to be able to use so few of the skills. We suggest two potential reasons.

\section{Lack of Practice}

Students may not have used these skills since they completed a whole page of examples as homework in high school or junior high. In fact, anecdotal evidence from classes in which we have exercised these skills often indicates that after a short explanation, students remember how to do the problems presented in classroom activities or homework. For example, students calculating the height of a tree using the distance from an observer and the angle to the top did not remember the formula for tangent, but several remembered enough to search on the Internet for trigonometric functions. With help from a few students who remembered using these functions, the rest of the class could calculate heights. Although trigonometry might not be considered a QL skill, many students have learned it, and this example demonstrates their ability to use it with a little prompting.

It is unclear, however, if one incidence of practicing these skills will make them available to students at later times. In a class on climate change, students did a classroom Spreadsheets Across the Curriculum module that required a power function. ${ }^{4}$ Students took an evaluation quiz before and after completing the module which was completed during one three-hour lab session in the middle of the semester. This four-question quiz showed improvement in understanding the skills used in the activity, from an average of one to three (Fig. 3), but at the end of the semester, when the same questions were asked, the scores reverted to the original level of one.

\footnotetext{
4 "Carbon Sequestration in Campus Trees" available at http://serc.carleton.edu/sp/ssac_home/general/examples/14323.html (accessed May 31, 2010).
} 


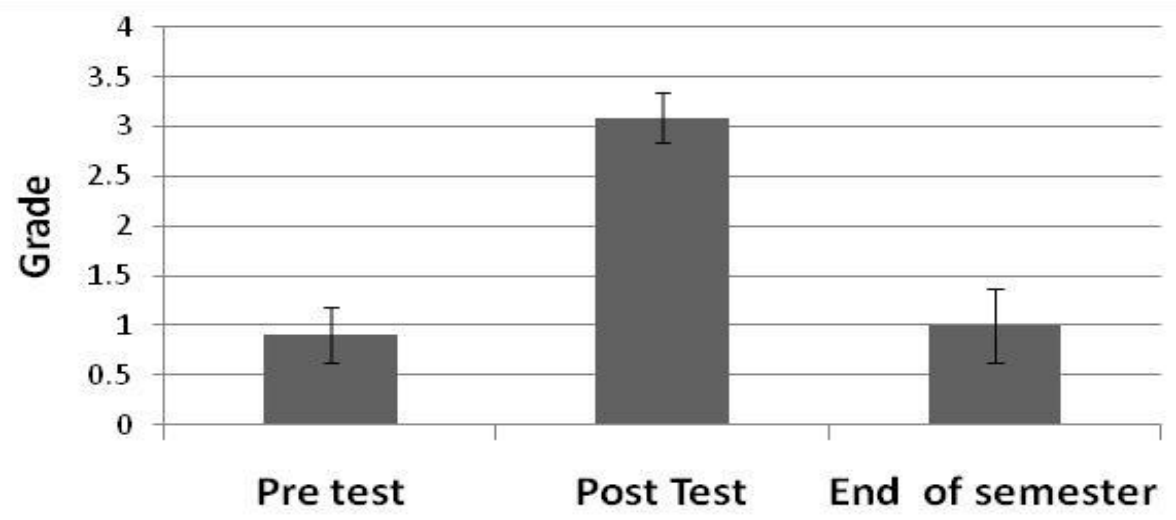

Figure 3. Student performance on a short quiz to assess the understanding of skills covered by a classroom activity. The pre-test was given before starting the activity. It was repeated immediately after the activity and again at the end of the semester.

\section{Use of Calculators}

Calculators are often the scapegoat for a lack of math skills, although much research has shown their value in increasing students' understanding of concepts (Ellington 2003; Hembree and Dessart 1986; however, see, e.g., Penglase and Arnold 1996). Although calculators may help one to understand concepts, it is not clear whether reliance on calculators hinders one's calculating ability and thus rapid solution of simple problems. For example, in an introductory biology class, another Spreadsheets Across the Curriculum module-this one on population growth $^{5}$-asked students to calculate how many birds would fit on an island if each bird required 0.1 hectare and the island is 267 hectares. Almost half of the students required help on this step. The same problem persists in upper-level classes. In a 300-level ecology class, a population matrix model exercise during one lab asked students to reduce the survival of juveniles, which was 0.5 , by 10 percent. Again, few of these juniors or seniors were able to do this correctly. In this case, I [B.S.] asked three similar questions on the final exam (Table 8) as extra credit and found that the students could answer less than two-thirds of them correctly. We do not know for sure if these weaknesses derive from a reliance on

\footnotetext{
5 "Introducing Endangered Birds to Ulva, NZ:Modeling exponential and logistic growth of the yellowhead population," available at http://serc.carleton.edu/sp/ssac_home/general/examples/19171.html (accessed May 31, 2010).
} 
calculators, but it seems possible, and several students asked if they could borrow one.

\section{Table 8}

Extra-Credit Math Questions Asked

in an Upper-Level Ecology Class

1. What is $10 \%$ less than 0.7 ?

2. What is $20 \%$ less than 200 ?

3. What is $5 \%$ less than 0.01 ?

Average correct answers, $1.7, N=15$

\section{Prescription: What Should We Do?}

If these results are found to apply to other institutions, they indicate a failure of our education system, and we should decide how to improve the situation. We make three suggestions.

1. Increase assessment of quantitative skills. Assessment and evaluation are becoming more and more common, especially in light of government and accreditation pressure. The results need to be published so we can evaluate whether the gap between student abilities and our expectations is widespread.

2. Include more quantitative skills in the curriculum. Our analysis indicates that skills need to be practiced repeatedly, not just once during a college career, in order to have a lasting effect on student abilities. Such repetition is a difficult goal, as there are many disciplines competing to increase their content in the curriculum. In our case, we found that raising awareness, providing support, and presenting workshops in which faculty in many disciplines developed activities for their classes (Steele and KiliçBahi 2008) increased the amount of QL included in the curriculum.

3. Finally, we must collaborate with math educators at the high school, junior high and even grade school levels to make sure that math is taught in a way that results in better retention and understanding of concepts. This is a lofty goal and must be driven by rigorous research on what techniques are most successful.

If our results turn out to be general across U.S. colleges, students' low abilities in math and utilitarian quantitative skills represent a significant weakness of our education system. Change will be slow and partial, but it is important. According 
to Schneider (2004), "Whatever strategy we choose, we must recognize that it really is malpractice to allow students to slip through college without developing the ability to use quantitative strategies to examine significant questions. We are only shortchanging our graduates with respect to the actual demands of a numbers-infused world."

\section{Acknowledgements}

The authors are grateful to the other members of the QL team at Colby-Sawyer who not only helped administer tests but also made the program possible: Peter White, Cheryl Coolidge, Lynn Garrioch, Joe Carroll, John Callewaert, and Randy Hanson. Many other faculty members contributed to the design and execution of this program. Amy Thelk analyzed the test and survey data. This program was made possible by NSF DUE 0633133, "Quantitative Literacy Across the Curriculum." The Spreadsheets Across the Curriculum modules were developed in NSF DUE 0442629. We thank Pranoti Asher, Corrine Taylor, Emily Lardner, two anonymous reviewers, and the editors of Numeracy for suggesting improvements to the manuscript.

\section{References}

Ball, D. L. 2003. Mathematical Proficiency for All Students. Santa Monica, CA: RAND Mathematics Study Panel.

Bennett, J., and B. Briggs. 2009. Using and Understanding Mathematics - A Quantitative Reasoning Approach. Fourth Edition, Addison Wesley Longman.

Bressoud, D. 2009. Establishing the quantitative thinking program at Macalester. Numeracy, 2(1): Article 3. http://dx.doi.org/10.5038/1936-4660.2.1.3

Ellington, A. J. 2003. A meta-analysis of the effects of calculators on students' achievement and attitude levels in precollege mathematics classes. Mathematics Education Research Journal, 34(5): 433-463. http://dx.doi.org/10.2307/30034795

Grawe, N. D., N. S. Lutsky, and C. J. Tassava. 2010. A rubric for assessing quantitative reasoning in written arguments. Numeracy, 3(1): Article 3. http://dx.doi.org/10.5038/1936-4660.3.1.3 
Hembree, R., and D. J. Dessart. 1986. Effects of hand-held calculators in precollege mathematics education: A meta-analysis. Journal for Research in Mathematics Education, 17(2): 83-99. http://dx.doi.org/10.2307/749255

Hughes-Hallett, D. 2001. Achieving numeracy: the challenge of implementation. In Mathematics and Democracy, ed. L. A. Steen, 93-98. Princeton, NJ: National Council on Education and the Disciplines.

Madison, B. L. 2009. All the more reason for QR across the curriculum. Numeracy 2(1): Article 1. http://dx.doi.org/10.5038/1936-4660.2.1.1

Penglase, M., and S. Arnold. 1996. The graphics calculator in mathematics education: A critical review of recent research. Mathematics Education Research Journal, 8(1): 58-90.

Schneider, C. G. 2001. Setting greater expectations for quantitative learning. Peer Review. Summer. http://www.aacu.org/peerreview/pr-su04/prsu04feature3.cfm, accessed May 31, 2010

Steele, B., and S. K1lıç-Bahi. 2008. Quantitative literacy across the curriculum: A case study. Numeracy, 1(2): Article 3. http://dx.doi.org/10.5038/1936$\underline{4660.1 .2 .3}$

Steen, L. A. 2007. Selected Quantitative Literacy Programs in U. S. Colleges and Universities. http://www.stolaf.edu/people/steen/Papers/qlprogs.pdf, accessed May 31, 2010)

Sundre, D. L., and A. Kitsantas. 2004. An exploration of the psychology of the examinee: Can examinee self-regulation and test-taking motivation predict consequential and non-consequential test performance? Contemporary Educational Psychology, 29(1): 6-26. http://dx.doi.org/10.1016/S0361476X(02)00063-2

Tapia, M., and G. E. Marsh. (2004). An instrument to measurement mathematics attitudes. Academic Exchange Quarterly, 8 (2). http://www.rapidintellect.com/AEQweb/cho253441.htm, accessed May 31, 2010)

Taylor, C. 2009. Assessing quantitative reasoning. Numeracy, 2(2): Article 1. http://dx.doi.org/10.5038/1936-4660.2.2.1

Wallace, D., K. Rheinlander, S. Woloshin, and L. Schwartz. 2009. Quantitative literacy assessments: an introduction to testing tests. Numeracy 2(2): Article 3. http://dx.doi.org/10.5038/1936-4660.2.2.3 